Research Article, Issue 1
Analytical Methods in Environmental Chemistry Journal
Journal home page: www.amecj.com/ir

\title{
Investigation of Adsorption of Cobalt-phthalocyanine from Aqueous Waste Stream Using UVM-7/Ag
}

\author{
Amir Vahid ${ }^{\mathrm{a}^{*}}$, Majid Abdous ${ }^{\mathrm{b}}$, and Shahnaz Nayyeri ${ }^{\mathrm{b}}$ \\ ${ }^{a}$ Research institute of petroleum industry, Tehran, Iran. \\ ${ }^{\mathrm{b}}$ Faculty of chemistry, Amirkabir University of Technology, Tehran, Iran.
}

\section{A R T I C L E I N F O:}

Received 21 Aug 2018

Revised form 12 Oct 2018

Accepted 19 Nov 2018

Available online 30 Dec 2018

Keywords:

Adsorption

Aqueous

Dye

Isotherm

Mesoporous silica

Kinetics

\begin{abstract}
A B S T RA C T
The effect adsorption of cobalt-phthalocyanine-3,4',4",4"'tetrasulfonicacid tetrasodium salt $\left[\mathrm{Co}(\mathrm{tsPc})^{-4} \cdot 4 \mathrm{Na}^{+}\right]$onto $\mathrm{UVM}-7 / \mathrm{Ag}$ mesoporous material was investigated. In addition, X-ray diffraction (XRD), scanning electron microscopy (SEM), and nitrogen adsorptiondesorption measurement were used to examine the morphology and the microstructure of the obtained composite. Various parameters including solution adsorbent dosage, contact time, initial dye concentration and temperature were systematically studied. Equilibrium data fitted well the Langmuir models; moreover, the fitness suggests that the adsorption be monolayer and physical in nature. Kinetic studies showed that the adsorption process could be better described by the Lagergren pseudosecond-order models. Thermodynamic constant values $(\Delta \mathrm{G}<0, \Delta \mathrm{H}<$ 0 and $\Delta \mathrm{S}<0$ ) demonstrated that the adsorption reactions of $\mathrm{Co}(\mathrm{tspc})^{-4}$ onto UVM-7/Ag were feasible, spontaneous, and exothermic under the examined conditions.
\end{abstract}

\section{Introduction}

Mercaptan and sulfur compounds present in the crude oil and petroleum cuts cause corrosion of pipes and different environmental pollutions[1]. There are various methods to remove mercaptan but the major one is the catalytic oxidation in the presence of caustic solution and air. phthalocyanine are effective catalysts for thiol and hydrosulfide oxidation by dioxygen[2-4]. Metal phthalocyanines (MPCS) are two dimensional (2D) organic macro cyclic molecular catalysts (MN4) with metal atoms

\footnotetext{
${ }^{*}$ Corresponding Author Email: avahid753@gmail.com https://doi.org/10.24200/amecj.v1.i01.34
}

at the center $[5,6]$.

One of the most important applications of MPCS has been in catalysis, including large-scale industrial processes. For instance, the Merox process, referred to as "sweetening" in the petroleum refining industry, involves catalytic oxidation of mercaptans in the presence of sulfonated cobalt phthalocyanines to remove a major part of sulfur from petrol [7]. The catalytic properties of MPCS depend on the metal and complex structure and can be tuned by appropriate structural modifications $[8,9]$. This is the basis of the redox mechanism of catalytic oxidation of sulfur-containing compound. 


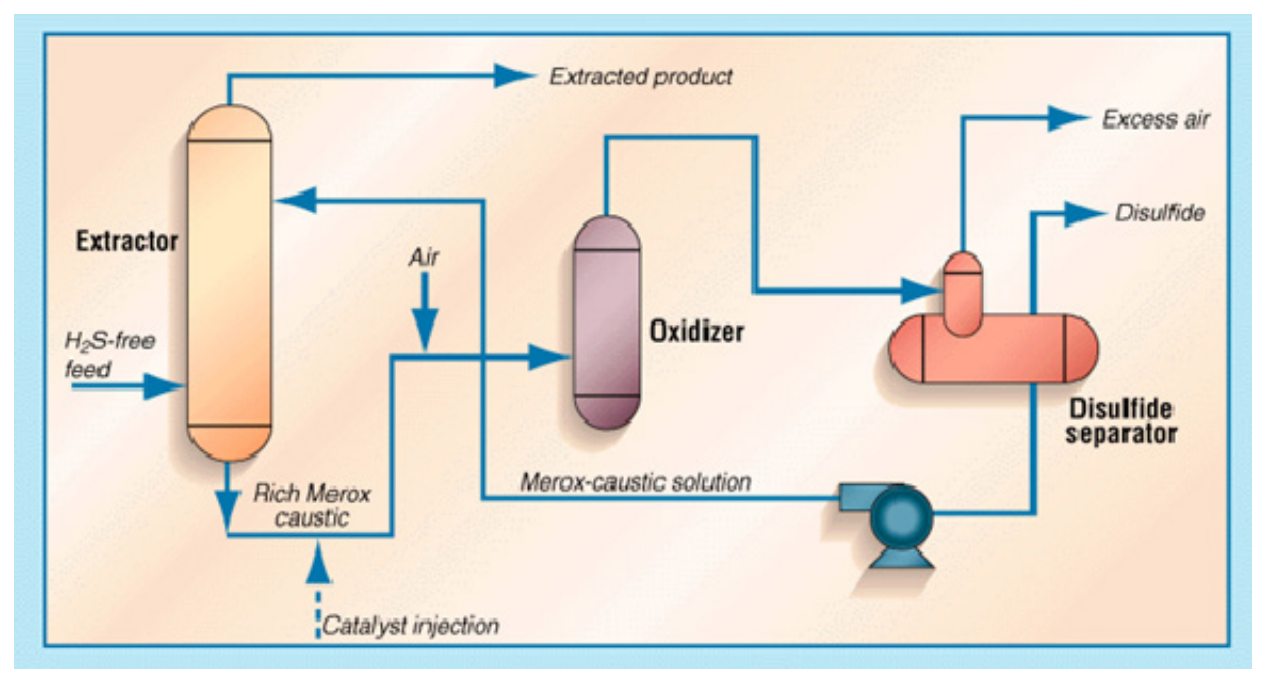

Fig. 1. Schematic representation of Merox unit.

These catalysts have found wide application in the catalytic oxidation of mercaptans in oil fraction as shown if Figure 1 [10].

In many systems using transition metal compounds as catalysts, the mechanism suggested by Wallace et al.[11] is:

$$
\begin{aligned}
& \mathrm{RSH}+\mathrm{NaOH} \rightarrow \mathrm{RS}^{-}+\mathrm{H}_{2} \mathrm{O} \\
& \mathrm{RS}^{-}+\mathrm{CO}^{+3} \rightarrow \mathrm{CO}^{+2}+\mathrm{RS}^{\bullet} \\
& 2 \mathrm{RS}^{\bullet} \rightarrow \mathrm{RSSR} \\
& \mathrm{O}_{2}{ }^{2}+\mathrm{H}_{2} \mathrm{O} \rightarrow 2 \mathrm{OH}^{-}+1 / 2 \mathrm{O}_{2}
\end{aligned}
$$

CoPChas a low solubility in water, the substitution of CoPc with hydrophilic sulfonic groups $\left[\mathrm{Co}(\mathrm{tsPc})^{-4}\right]$

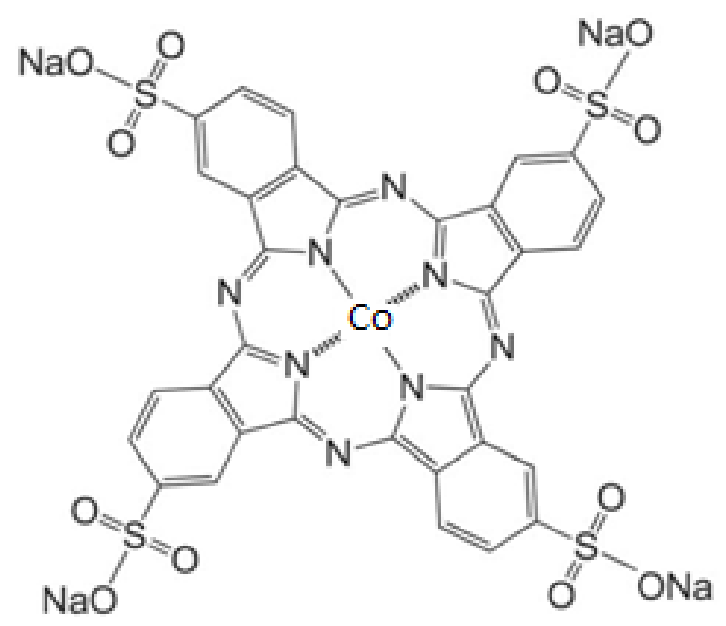

Fig. 2. Structure of the Co (II) tetra sulfophthalocyanine $\left[\mathrm{Co}(\mathrm{tsPc})^{-4} .4 \mathrm{Na}^{+}\right]$organometal. as shown if Figure 2, makes this derivative easily soluble in aqueous solution. sulfonated metal phthalocyanine (MSPC) complexes, highly watersoluble molecule and very well recognized for its unique physicochemical properties and wide range of applications ranging from catalysis to sensing and photocatalysis .

The Merox catalyst is a heterogeneous blue powder dissolved in water.

Merox catalyst of caustic solution creates problems that in this work, co (II) tetra sulfophthalo cyanine $\mathrm{Co}(\mathrm{TSP})^{-4}$ catalyst removal from caustic solutions by using meso porous silica UVM-7 is studied. Functionalized with $\mathrm{Ag}$ and, $\gamma$-Alumina was prepared by sol-gel method and the synthesized nanoparticle was characterized by scanning electron microscopy (SEM) and X-ray diffraction (XRD).

Mesoporous materials can have large adsorption capacity, excellent selectivity and improved powder recoverability for removal of toxic compounds from aqueous solutions[12, 13]. The effects of adsorbent dosage, initial $\mathrm{Co}(\mathrm{tspc})^{-4}$ concentration and contact time were studied. The adsorption was fit to different adsorption isotherms and also to kinetics of the adsorption was studied. Parameters affecting the removal of $\mathrm{Co}(\mathrm{tspc})^{-4}$ from the aqueous solution was investigated and validated by 
using three factorial Box-Behnken Design (BBD).

\section{Experimental}

\subsection{Synthesis and characterization}

The general procedure for the synthesis of UVM7 is the atrane route, in which the presence of the polyalcohol is the key to balancing the hydrolysis and condensation reaction rates [18]. In a typical synthesis, TEOS was added to determined amounts of $\mathrm{TEAH}_{3}$ (tri ethanolamine). The solution was heated up to $140^{\circ} \mathrm{C}$ under vigorous stirring. After cooling down to $90^{\circ} \mathrm{C}, \mathrm{CTAB}$ (cetyl trimethylammonium bromide) was added to this solution. After that, water was added slowly to this solution under stirring until a white suspension resulted. This suspension was aged for 4 hours at room temperature. The solid was filtered, washed with sufficient amounts of water and acetone and dried in an oven at $80^{\circ} \mathrm{C}$ overnight. Thermo calcination of the as synthesized UVM-7 was carried out under a flow of air up to $550^{\circ} \mathrm{C}$ for 6 hours with a heating rate of $1 \mathrm{C} / \mathrm{min}$ to remove both the surfactant and $\mathrm{TEAH}_{3}$ from the as-synthesized UVM-7. The final molar composition of the reactants was 1.0 TEOS : $3.5 \mathrm{TEAH}_{3}: 0.25 \mathrm{CTAB}$ : $90 \mathrm{H}_{2} \mathrm{O}$.

\subsection{Modification of $U V M-7$}

For the modification of UVM-7 with Ag, 1 gram of calcined UVM-7 is mixed with $100 \mathrm{~mL}$ of distilled water contains 0.1 gram of $\mathrm{AgNO}_{3}$ and stirred for 24 hours. The water was distilled using and automatic evaporator and calcined at $450{ }^{\circ} \mathrm{C}$ for 5 hours.

\section{Results and Discussion}

\subsection{Characterization UVM-7/Ag}

TEM image of UVM-7/Ag is displayed in Figure

3. Mesochannels of the UVM-7 is obviously visible in this image. Furthermore, dark points in the image related to the higher contrast of heavy silver atoms with incident electron beam. BET surface area of the calcined UVM/7 was $838 \mathrm{~m}^{2} \mathrm{~g}^{-1}$

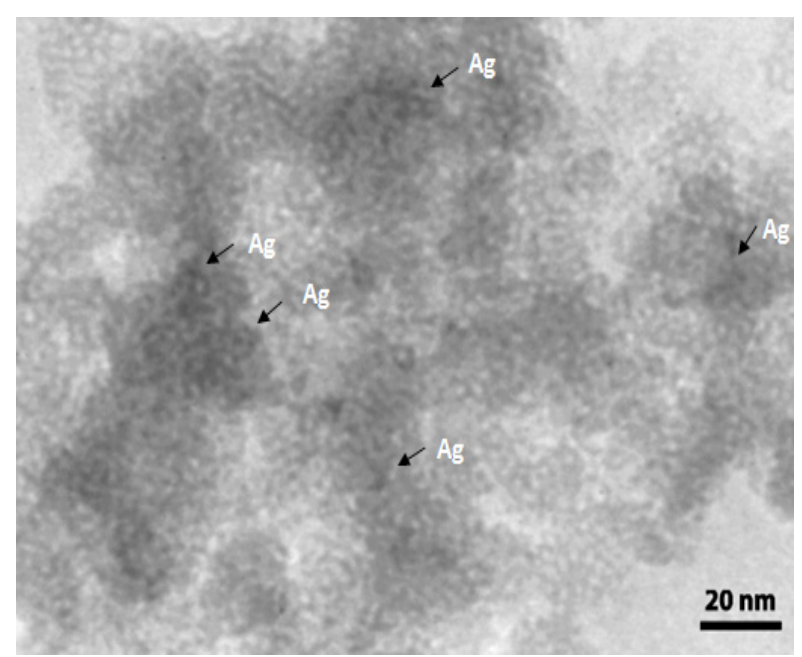

Fig. 3. TEM image of UVM-7/Ag.

which reached to $601 \mathrm{~m}^{2} \mathrm{~g}^{-1}$ after doping with silver. These are direct and indirect evidences of formation of ordered UVM-7 which contains silver nanoparticles.

XRD pattern of the as-synthesized and calcined UVM-7 are illustrated in Figure 4. As can be seen, a sharp peak at low angle about $1.5 \times 2$ theta is characteristic of mesoporous materials. In case of calcined UVM-7 higher order diffraction, i.e. $d_{110}$ and $d_{200}$ are sign of better structural order which is usually seen in mesoporous materials after thermocalcination and condensation of silanol groups.

\subsection{Adsorption studies}

Adsorption behavior was studied by a batch method, which parameters that influence the adsorption process such as contact time, initial concentration, adsorbent dose, surfactant template, and reaction temperature was investigated. In addition, aqueous solutions of $\mathrm{Co}(\mathrm{tsPc})^{-4}$ which its chemical structure is shown in Figure 1; moreover, with concentration ranging from 100 to $500 \mathrm{mg} \mathrm{L}^{1}$ were prepared by dissolving $\mathrm{Co}(\mathrm{tsPc})^{-4}$ in double distilled water. In each adsorption experiment, $10 \mathrm{mg}$ adsorbent was

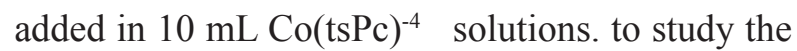
effect of temperature the adsorption was carried out at four different temperatures $(27,35,40$ and $50{ }^{\circ} \mathrm{C}$ ) and for contact time studies the samples 


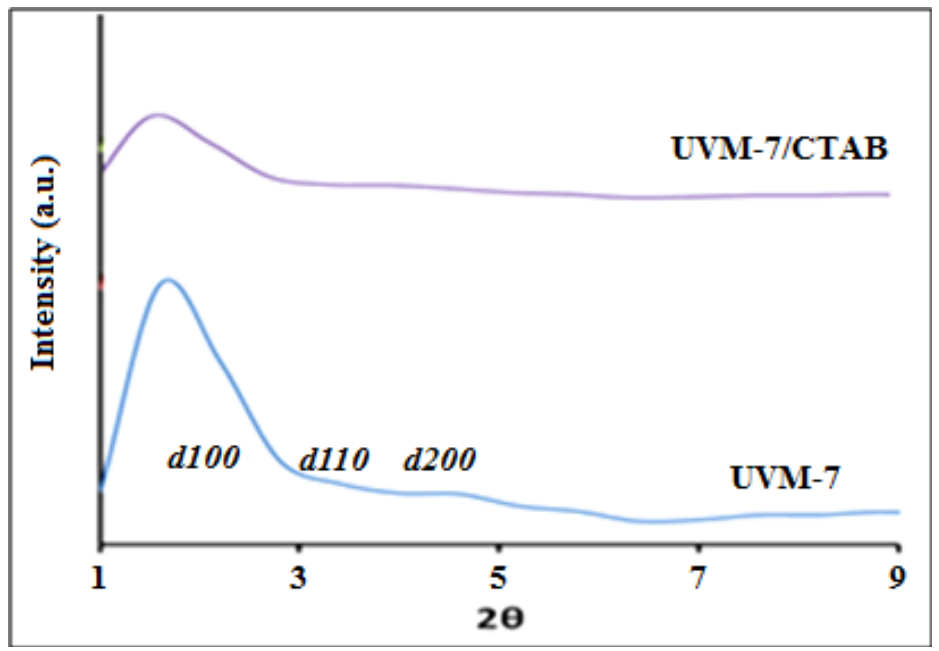

Fugire 4. XRD pattern of as-synthesized and calcined UVM-7.

were taken at predetermined time intervals $(10,20$, $30,40,60,80$ and $100 \mathrm{~min})$. After equilibrium, the concentration of the adsorbate in the residual solution was analyzed by a UV-spectrophotometer at $\lambda$ max of $661 \mathrm{~nm}$. The amount of $\mathrm{Co}(\mathrm{tsPc})^{-4}$ adsorbed per unit mass of UVM-7/Ag the qe (mg $\mathrm{g}^{-1}$ ) was calculated by the following equation:

$$
q_{e}=\frac{\left(c_{0}-c_{t}\right) V}{M}
$$

where $\mathrm{q}_{\mathrm{e}}$ is the adsorption capacity $\left(\mathrm{mg} \mathrm{g}^{-1}\right)$ of the adsorbent at equilibrium; $\mathrm{C}_{0}$ and $\mathrm{C}_{\mathrm{e}}$ are the initial and equilibrium concentrations of solute $\left(\mathrm{mg} \mathrm{L}^{-1}\right)$ respectively. Also, $\mathrm{V}$ is the volume of the aqueous solution (L). and $\mathrm{W}$ is the mass ( $\mathrm{g}$ ) of adsorbent used in the experiments.

The adsorptive removal efficiency (R) was determined according to the following equation:

$$
R=\frac{\left(c_{0}-c_{t}\right)}{c_{o}} \times 100
$$

\subsubsection{Effect of adsorbent dosage}

The effect of adsorbent dosage $(\mathrm{m})$ on the amount of $\mathrm{Co}(\mathrm{tsPc})^{-4}$ adsorbed at equilibrium (qe, $\mathrm{mg}$ $\mathrm{g}^{-1}$ ), was investigated by adding different weights of adsorbent UVM-7/Ag into $10 \mathrm{ml}$ of solution $500 \mathrm{mg} \mathrm{l}^{-1} \mathrm{Co}(\mathrm{tsPc})^{-4}$ and shaking the mixture for $60 \mathrm{~min}$ at ambient temperature. It is evident from figure 5، qe increases by increasing $\mathrm{m}$, can be attributed to the availability of greater surface area and more adsorption sites. that adsorption capacity of $\mathrm{Co}(\mathrm{tspc})^{-4}$ increased when UVM-7/Ag dosage varied from $2 \mathrm{mg}$ to $10 \mathrm{mg}$. However, the

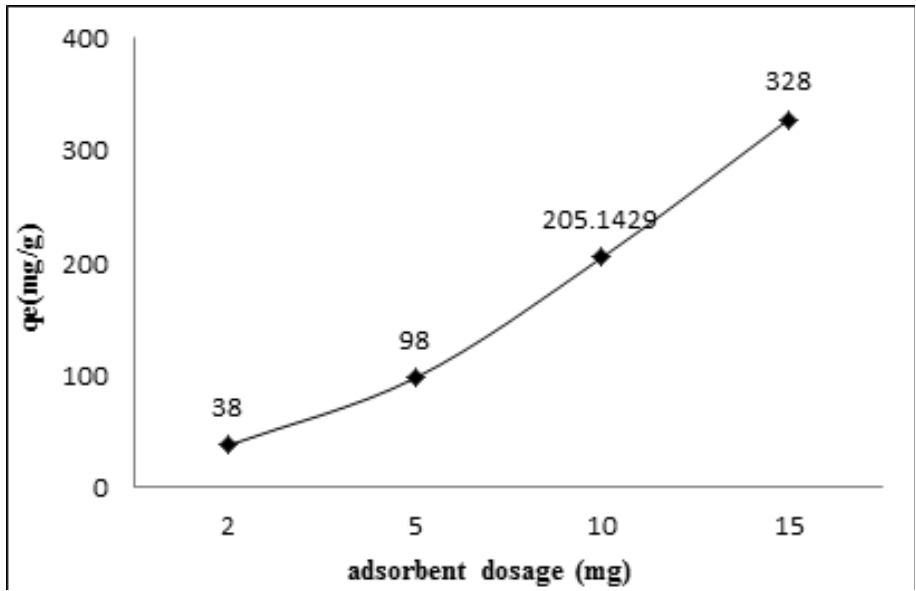

Figure 5. .Effect of adsorbent dosage on the adsorption of $\mathrm{Co}(\mathrm{tsPc})^{-4}$ by UVM-7/Ag. 
adsorption capacity slowly as the adsorbent dosage increased from $10 \mathrm{mg}$ to $15 \mathrm{mg}$. Thus $10 \mathrm{mg}$ was chosen as the optimal UVM-7/Ag dosage in this study[14].

\subsubsection{Effect of contact time}

It is visible from Figure 6, that the amount of the adsorbed $\mathrm{Co}(\mathrm{tsPc})^{-4}$ increases with time and then reaches a constant value. At this point, the amount of $\mathrm{Co}(\mathrm{tsPc})^{-4}$ desorbing from the adsorbent is in a state of dynamic equilibrium with the amount of $\mathrm{Co}(\mathrm{tsPc})^{-4}$ being adsorbed onto the mesoporous. The time required to attain this state of equilibrium is termed equilibrium time. estimate equilibration time for Calculation maximum adsorption Capacity and to know the kinetics of the adsorption It is seen that the rate of uptake is rapid.Required at the beginning, and time required for equilibrium adsorption is $60 \mathrm{~min}$. The adsorption rate was related to the content of the active adsorption sites on the matrix of the adsorbent[15].

\subsubsection{Effect of temperature}

The effect of temperature on the adsorption of $\mathrm{Co}(\mathrm{tsPc})^{-4}$ onto UVM-7/Ag was investigated by adding $10 \mathrm{mg}$ of the adsorbent into $10 \mathrm{~mL}$ of solution $500 \mathrm{mg} \mathrm{L}^{-1} \mathrm{Co}(\mathrm{tsPc})^{-4}$ and shaking the mixture for $60 \mathrm{~min}$ at different temperatures of 27, 35, 40 and $50{ }^{\circ} \mathrm{C}$ in a water bath. The results indicated that the equilibrium adsorption amount $\left(\mathrm{q}_{\mathrm{e}}\right)$ decreases with increasing temperature (Figure 7), indicating that the adsorption process is exothermic in nature[16]. In order to understand the effect of temperature on the adsorption process, thermodynamic parameters should be determined at various temperatures. For this reason, three basic thermodynamic parameters

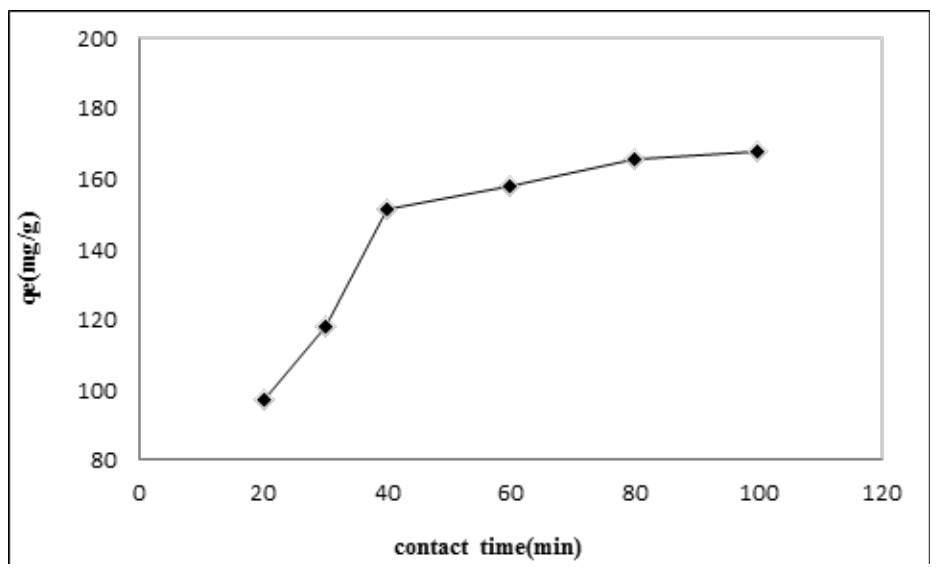

Fig. 6. Effect of contact time on the adsorption of $\mathrm{Co}(\mathrm{tsPc})^{-4}$ by UVM-7/Ag

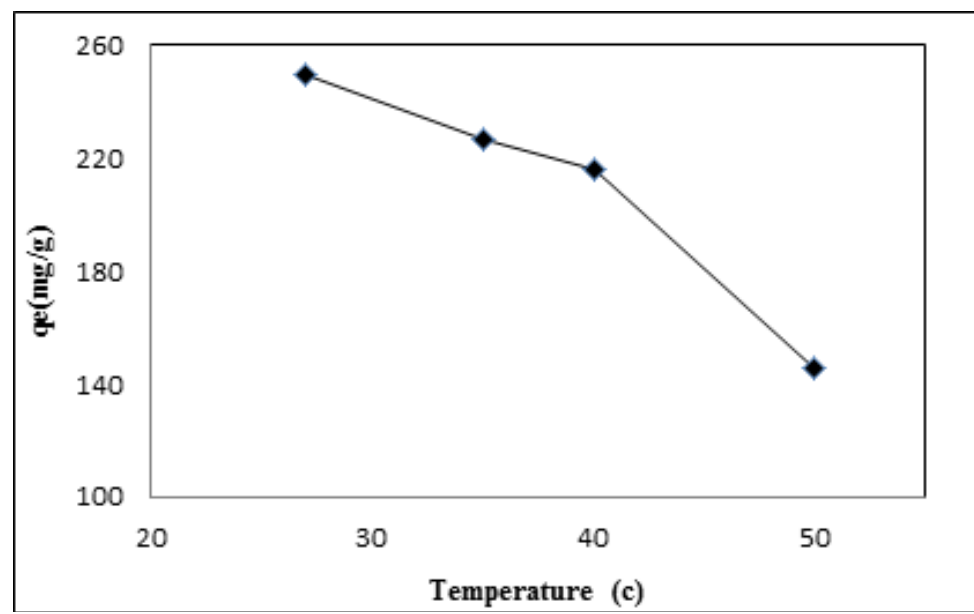

Fig. 7 .Effect temperature on the adsorption of $\mathrm{Co}(\mathrm{tsPc})^{-4}$ by UVM-7/Ag 
were studied: the Gibbs free energy of adsorption $(\Delta \mathrm{G})$, the enthalpy change $(\Delta \mathrm{H})$, and the entropy change $(\Delta S)$. The Gibbs free energy change of the adsorption process is related to the equilibrium constant $\left(\mathrm{K}_{\mathrm{c}}\right)$. The thermodynamic parameters $\Delta \mathrm{G}, \Delta \mathrm{S}$ and $\Delta \mathrm{H}$ for this adsorption process were calculated from the following equations:

$\Delta \mathrm{G}=-R T \ln K C$

where $\mathrm{R}$ is the gas constant $\left(8.314 \mathrm{~J} \mathrm{~mol}^{-1} \mathrm{~K}^{-1}\right), \mathrm{T}$ is the absolute temperature. $\mathrm{K}_{\mathrm{c}}$ values were estimated as $\mathrm{Kc}=\mathrm{Ca} / \mathrm{Cb}$

where $\mathrm{C}_{\mathrm{a}}$ is the equilibrium concentration of $\mathrm{Co}(\mathrm{tsPc})^{-4}$ on adsorbent $\left(\mathrm{mg} \mathrm{L}^{-1}\right), \mathrm{C}_{\mathrm{b}}$ is the equilibrium concentration of $\mathrm{Co}(\mathrm{tsPc})^{-4}$ in the solution $\left(\mathrm{mg} \mathrm{L}^{-1}\right)$. the $\Delta \mathrm{H}$ and $\Delta \mathrm{S}$ values were calculated from slope and intercept of the linear plot of $\ln \mathrm{K}_{\mathrm{c}}$ versus $1 / \mathrm{T}[17,18]$.

$\ln K c=-\Delta \mathrm{H} / R T+{ }^{\Delta \mathrm{S}} / R$

The corresponding values of thermodynamic parameters are presented in Table 1. It shows that $\Delta \mathrm{H}, \Delta \mathrm{S}$ and $\Delta \mathrm{G}$ are negative for all experiments. The negative value of the standard enthalpy change for $\mathrm{Co}(\mathrm{tsPc})^{-4}$ sorption indicates exothermic nature of adsorption[19] .The values of $\Delta \mathrm{G}$ were calculated to be $-6.3,-5.4,-4.4,-3.7 \mathrm{~kJ} \mathrm{~mol}^{-1}$ at the temperatures of $300,308,313$ and $323 \mathrm{~K}$, respectively. The negative $\Delta \mathrm{G}$ indicates that the adsorption is a spontaneous process. The increase of $\Delta \mathrm{G}$ values with rising temperature demonstrate a negative influence of temperature on the adsorption reaction. Moreover, negative $\Delta \mathrm{S}$ values indicate a reduction of randomness at the solidliquid interface during the adsorption process[20].
Therefore the optimal reaction temperature was $300 \mathrm{~K}$.

\subsubsection{Effect of initial dye concentration}

The effect of initial $\mathrm{Co}(\mathrm{tsPc})^{-4}$ concentration on adsorption behaviors was investigated in Figure 8. It can be seen that the majority of $\mathrm{Co}(\mathrm{tsPc})^{-4}$ was removed by UVM-7/Ag in lower initial $\mathrm{Co}(\mathrm{tsPc})^{-4}$ concentration, the $\mathrm{Co}(\mathrm{tsPc})^{-4}$ removal efficiency decreased with increase initial $\mathrm{Co}(\mathrm{tsPc})^{-4}$ concentration. also This effect can has been attributed to the ratio of surface active site to the total $\mathrm{Co}(\mathrm{tsPc})^{-4}$ ions in the solution .while The result reveals that the amount of capacity adsorbed (qe) increases as the concentration increases. The initial concentration of $\mathrm{Co}(\mathrm{tsPc})^{-4}$ can serve as an essential driving force for overcoming the mass transfer resistance of dye molecules between the aqueous solution and solid-phase adsorbent. As the initial concentrations of $\mathrm{Co}(\mathrm{tsPc})^{-4}$ increased, the driving force became higher as well, which facilitated more dye molecules adsorbing onto the adsorbent, contributing to better adsorptive removal performance and higher adsorption capacity[21].

\subsection{Effect of presence of surfactant template}

When the surfactants in aqueous solution are beyond the critical micelle concentrations (CMC), micelles are formed and they act as templates for preparing UVM-7 materials. The existence of cationic template within the framework of UVM7 materials causes the change in the surface chemistry and porosity of the sorbate, which in turn affects the sorption behavior of sorbate. CTAB/ UVM-7 possesses high adsorption energy of

Table 1. Thermodynamics parameters for $\mathrm{Co}(\mathrm{tspc})^{-4}$ adsorption onto UVM-7/Ag

\begin{tabular}{cccc}
\hline & \multicolumn{3}{c}{ Thermodynamics quantities } \\
\cline { 2 - 4 } Temperature $(\mathrm{k})$ & $\Delta \mathrm{H}\left(\mathrm{KJ} \mathrm{mol}^{-1}\right)$ & $\Delta \mathrm{G}\left(\mathrm{kj} \mathrm{mol}^{-1}\right)$ & $\Delta \mathrm{S}\left(\mathrm{kj} \mathrm{mol}^{-1} \mathrm{k}^{-1}\right)$ \\
\hline 300 & -21.976 & -6.3 & -0.099 \\
308 & -21.976 & -5.4 & -0.099 \\
313 & -21.976 & -4.4 & -0.099 \\
323 & -21.976 & -3.7 & -0.099 \\
\hline
\end{tabular}




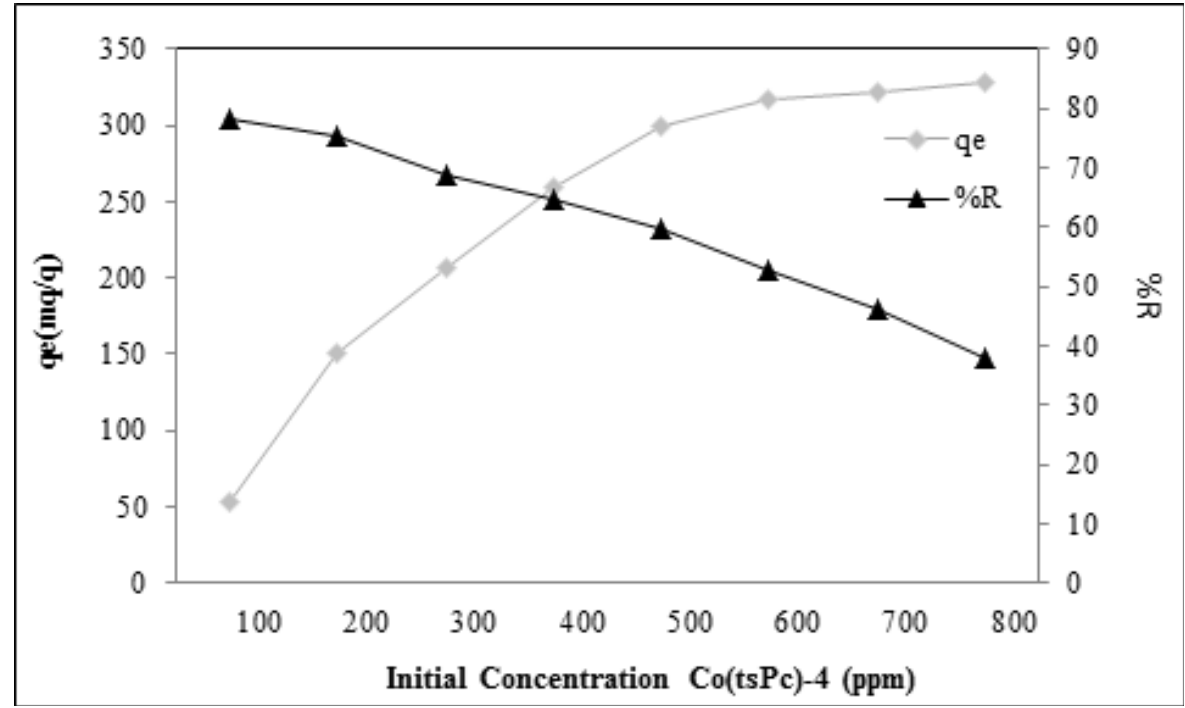

Figure 8. Effect initial concentration on the adsorption of $\mathrm{Co}(\mathrm{tsPc})^{-4}$ by UVM-7/Ag.

quaternary alkyl ammonium groups $(\mathrm{Si}-\mathrm{C}-\mathrm{C}-\mathrm{C}-$ [ $\left.\left.\mathrm{N}^{+}-(\mathrm{CH} 3) 3\right]\right)$ contributed from cationic template. Apparently, the surfactant template can alter the surface chemistry and population of sorption sites of the materials. The cationic templates improve the sorption towards those species containing anionic groups. It is known that hydrophobicity, electrostatic interactions, $\mathrm{p}-\mathrm{p}$ interactions, hydrogen bonding, dipole-dipole interactions, steric hindrance as well as a combination of them, are among the most important interactions which determine the retention behavior of substances in the absorbent. When the adsorbent is CTABcontaining mesoporous silica, the aromatic cycles could interact with the alkyl part of CTAB by hydrophobicity; the sulfonic acid groups interact with the positive polar heads of surfactants by electrostatic interactions. It is mentioned multiple interactions which give the surfactant-containing adsorbent excellent adsorption capability. As shown if Figure 9, The adsorption capacity of "calcined" adsorbent is weak and is generally due to the van der Waals interactions present between the molecules of dyes and adsorbent [22].

\subsection{Adsorption isotherms}

To optimize the design of an adsorption system for the adsorption of dyes, various isotherm equations like those of Freundlich, Langmuir and Temkin have been used to describe the equilibrium characteristics of the adsorption. For describing the relationship between the amount of adsorbate adsorbed on adsorbents at equilibrium $\left(\mathrm{q}_{\mathrm{e}}\right)$ and the concentration $\mathrm{cu}(\mathrm{tspc})^{-4}$ of the remaining in aqueous solution $\left(\mathrm{c}_{\mathrm{e}}\right)$. The Langmuir relation assumes monolayer sorption on to the homogeneous surface with a specific number of equivalent sites. The Langmuir isotherm[23] is represented by the following linear equation:

$$
\frac{\mathcal{C}_{e}}{q_{e}}=\frac{1}{b q_{m}}+\frac{\mathcal{c}_{e}}{q_{m}}
$$

where $\mathrm{C}_{\mathrm{e}}\left(\mathrm{mgL}^{-1}\right)$ is the equilibrium concentration, qe $\left(\mathrm{mgg}^{-1}\right)$ the amount of adsorbate adsorbed per unit mass of adsorbent, $\mathrm{qm}\left(\mathrm{mg} \mathrm{g}^{-1}\right)$ is the Langmuir constant representing maximum monolayer capacity and $b$ is the Langmuir constant related to the energy of adsorption. The Langmuir constants $b$ and $\mathrm{q}_{\mathrm{m}}$ were calculated from this isotherm and their values are listed in Table 2. The Freundlich isotherm is derived by assuming a heterogeneous surface with a nonuniform distribution of heat of adsorption over the surface. Finally, the Freundlich isotherm as follows: 


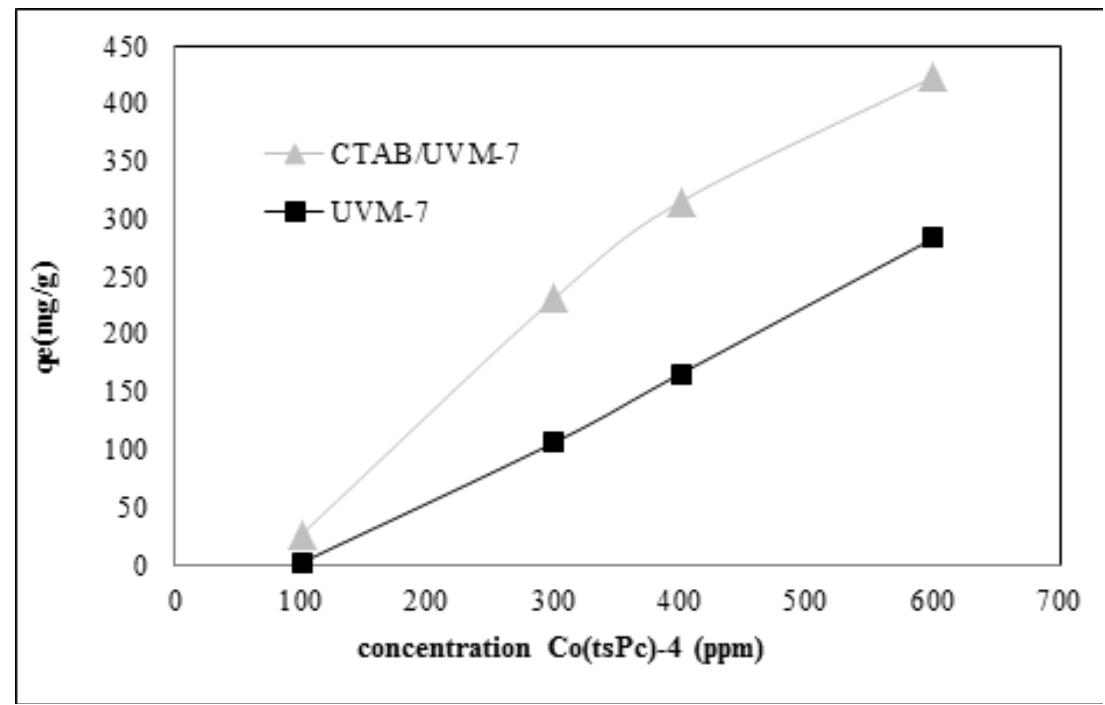

Fig. 9. Effect presence of surfactant template.

$$
\log q_{e}=\log k_{F}+\frac{1}{n} \log c_{e}
$$

where $\mathrm{K}_{\mathrm{f}}$ is the Freundlich constant $\left(\mathrm{mg} \mathrm{g}^{-1}\left(\mathrm{mg} \mathrm{L}^{-1}\right)\right.$ $\left.{ }^{n}\right)$ and $1 / n$ is the heterogeneity factor. The slope $1 / n$ ranging between 0 and 1 is a measure of adsorption more intensity or surface heterogeneity, becoming heterogeneous as its value gets closer to zero. The plot of $\log$ qe versus $\log \mathrm{Ce}$, gives straight lines with slope $1 / \mathrm{n}$ [24].

The Temkin isotherm equation assumes that the heat of adsorption of all the molecules in the layer decreases linearly with coverage due to adsorbentadsorbate interactions, and that the adsorption is characterized by a uniform distribution of the binding energies, up to some maximum binding energy $[25,26]$. Temkin isotherm is given as:

$\mathrm{q}_{\mathrm{e}}=\mathrm{B} \ln \mathrm{K}_{\mathrm{t}}+\mathrm{B} \ln \mathrm{C}_{\mathrm{e}}$

$\mathrm{K}_{\mathrm{t}}$ is the equilibrium binding constant $\left(\mathrm{Lmg}^{-1}\right)$ corresponding to the maximum binding energy, and constant $\mathrm{B}$ is related to the heat of adsorption. From Table 2, the Langmuir isotherm model yielded the best fit with the highest $\mathrm{R}^{2}$ value (0.99) compared to the other two models.

\subsection{Adsorption kinetics}

The study of adsorption kinetics is desirable as it provides information about the mechanism of the adsorption process such as mass transfer and chemical reaction. In this context, the mechanism of the adsorption of $\mathrm{Co}(\mathrm{tspc})^{-4}$ ion onto adsorbents, different kinetic models such as the pseudo-firstorder and pseudo-second-order has been studied. The pseudo- first-order equation can be used to determine the rate constant for the adsorption process and describe the initial stage of the adsorption processas follows [27]:

$$
\frac{1}{q_{t}}=\frac{k_{1}}{q_{e}}\left(\frac{1}{t}\right)+\frac{1}{q_{e}}
$$

where $q_{e}$ and $q_{t}$ are the amounts of adsorbed $\mathrm{Co}(\mathrm{tspc})^{-4}$ at equilibrium and any time $\mathrm{t}\left(\mathrm{mg} \mathrm{g}^{-1}\right)$, respectively, $\mathrm{k}_{1}$ is the equilibrium rate constant of the first-order sorption $\left(\mathrm{min}^{-1}\right)$.

The pseudo-second-order rate equation of can be represented in the following form [28, 29] :

$\frac{t}{q_{t}}=\frac{1}{k_{2} q_{e}^{2}}+\frac{1}{q_{e}} t$

where $\mathrm{K}_{2}\left(\mathrm{~g} \mathrm{mg}^{-1} \mathrm{~min}^{-1}\right)$ is the rate constant of the second-order equation, qt $\left(\mathrm{mg} \mathrm{g}^{-1}\right)$ and qe $\left(\mathrm{mg} \mathrm{g}^{-1}\right) \mathrm{Co}(\mathrm{tspc})^{-4}$ adsorbed at time $\mathrm{t}(\mathrm{min})$ and at equilibrium respectively [30]. Pseudo-secondorder kinetics is based on the adsorption capacity, 
Table 2. Isotherm parameters for Co(tspc $)^{-4}$ adsorption onto UVM-7/Ag.

\begin{tabular}{ccccccccr}
\hline \multicolumn{3}{c}{ Langmuir isotherm } & \multicolumn{3}{c}{ Freundlich isotherm } & \multicolumn{3}{c}{ Temkin isotherm } \\
$\begin{array}{c}\mathrm{qm} \\
\left(\mathrm{mg} \mathrm{g}^{-1}\right)\end{array}$ & $\begin{array}{c}\mathrm{b} \\
\left(\mathrm{L} \mathrm{mg}^{-1}\right)\end{array}$ & $\mathrm{R}^{2}$ & $\begin{array}{c}\mathrm{K}_{\mathrm{F}} \\
\left(\mathrm{mg} \mathrm{g}^{-1}\right)\end{array}$ & $\begin{array}{c}\mathrm{N} \\
\left(\mathrm{L} \mathrm{mg}^{-1}\right)\end{array}$ & $\mathrm{R}^{2}$ & $\begin{array}{c}\mathrm{K}_{\mathrm{T}} \\
\left(\mathrm{Lmg}^{-1}\right)\end{array}$ & $\mathrm{B}$ & $\mathrm{R}^{2}$ \\
\hline 188.8 & 0.441 & 0.99 & 77624.72 & 15.38 & 0.982 & 1.52 & 11.53 & 0.709 \\
\hline
\end{tabular}

which usually gives a good description of the whole adsorption process.

The rate constants and correlation coefficients of the two kinetic models can be obtained from the plot of experimental data (Table 3). The, pseudosecond-order kinetic with the higher correlation coefficient $\left(R^{2}\right)$ suggests that $\mathrm{cu}(\mathrm{tspc})^{-4}$ adsorption on to UVM-7/Ag predominantly follow the pseudosecond-order kinetic model.

\section{Conclusion}

Potential of UVM-7/Ag to adsorb Co(tspc $)^{-4}$ has been investigated in this study. Moreover, the adsorption of $\mathrm{Co}(\mathrm{tspc})^{-4}$ was depend on adsorbent surface characteristics, temperature, contact time, adsorbent mass, and the initial $\mathrm{Co}(\mathrm{tspc})^{-4}$ concentration in the solution. The adsorption kinetic studies showed that the adsorption process followed pseudo-second-order kinetic model. The Langmuir, Freundlich, and Temkin adsorption isotherm models were applied to the adsorption data of anionic dyes ont UVM-7/Ag. The Langmuir isotherm best fitted the adsorption equilibrium data for $\mathrm{Co}(\mathrm{tspc})^{-4}$; moreover, the fitness suggests that the adsorption be monolayer and physical in nature. In addition, the thermodynamic calculations demonstrated the feasible, spontaneous, and exothermic nature of the adsorption reaction.

\section{References}

[1] M. Mirzaeian, A.M. Rashidi, M. Zare, R. Ghabezi, R. Lotfi, Mercaptan removal from natural gas using carbon nanotube supported cobalt phthalocyanine nanocatalyst, J. Natur. Gas Sci. Eng., 18 (2014) 439-445.

[2] M. Chanda, A. Grinshpun, K. O'driscoll, G. Rempel, Polymer-supported metal complexes as catalysts for the oxidation of thiosalts by molecular oxygen: V. The polythiosemicarbazide-Cu (II) complex, J. Mol. Catal., 26 (1984) 267-76.

[3] N. Reid , R. Barat, Impact of Fluorinated Cobalt(II) Phthalocyanine Catalysts on Aerobic Thiol Oxidation Kinetics, Chem. Eng. Commun., 203 (2016) 714-723.

[4] V. Iliev, Catalytic oxidation of mercaptans by charcoalsupported sterically hindered cobalt (II)-phthalocyanines, J. mol.catal., 85 (1993) L269-L273.

[5] D. Klyamer, A. Sukhikh, S. Gromilov, P. Krasnov , T. Basova , Fluorinated metal phthalocyanines: interplay between fluorination degree, films orientation, and ammonia sensing properties, Sensors, 18 (2018) 1-13.

[6] A.B. Sorokin, Phthalocyanine metal complexes in catalysis, Chem. Rev., 113 (2013) 8152-8191.

[7] B. Basu, S. Satapathy, A. Bhatnagar, Merox and related metal phthalocyanine catalyzed oxidation processes, Catal. Rev. Sci. Eng., 35 (1993) 571-609.

[8] Z. Tang, W. Wu, K. Wang, Review: oxygen reduction reaction catalyzed by noble metal clusters, Catalysts, 8 (2018) 1-18.

[9] Y. Cheng, J. Veder, L. Thomsen, S. Zhao, M. Saunders, R. Demichelis, C. Liu, R. De Marco, S. P. Jiang, Electrochemically substituted metal phthalocyanines, e-MPc $(\mathrm{M}=\mathrm{Co}, \mathrm{Ni})$, as highly active and selective catalysts for CO2 reduction, J. Mater. Chem. A, 6 (2018) 1370-1375.

Table 3. Kinetic parameters for Co(tspc $)^{-4}$ adsorption onto UVM-7/Ag.

\begin{tabular}{cccccc}
\hline \multicolumn{2}{c}{ pseudo-first-order kinetics } & \multicolumn{3}{c}{ pseudo-second-order kinetic } \\
$\begin{array}{c}\text { qe } \\
\left(\mathrm{mg} \mathrm{g}^{-1}\right)\end{array}$ & $\begin{array}{c}\mathrm{K}_{1} \\
\left(\mathrm{~L} \mathrm{~min}^{-1}\right)\end{array}$ & $\mathrm{R}^{2}$ & $\begin{array}{c}\text { qe } \\
\left(\mathrm{mg} \mathrm{g}^{-1}\right)\end{array}$ & $\begin{array}{c}\mathrm{K} 2 \\
\left(\mathrm{~g} \mathrm{mg}^{-1} \mathrm{~min}^{-1}\right)\end{array}$ & $\mathrm{R}^{2}$ \\
\hline 250 & 29.5 & 0.957 & 250 & 0.000149 & 0.982 \\
\hline
\end{tabular}


[10] A. Leitão, A. Rodrigues, Studies on the Merox process: Kinetics of n-butyl mercaptan oxidation, Chem. Eng. Sci., 44 (1989) 1245-1253.

[11] T. Wallace, A. Schriesheim, H. Hurwitz, M. Glaser, Base-Catalyzed Oxidation of Mercaptans in Presence of Inorganic Transition Metal Complexes, Ind. Eng. Chem. Process Des. Dev., 3 (1964) 237-241.

[12] M. Anbia, K. Mohammadi, An effective method for removal of dichromate ion and furfural from aqueous solutions using a nanoporous adsorbent, Asian J. Chem., 21(2009) 3347-3356.

[13] M. Anbia, M.K. Rofouei, S.W. Husain, Mesoporous lanthanum tungstate as a novel sorbent for removal of heavy metal ions from aqueous media. Asian J. Chem., 19 (2007) 3862-3873.

[14] D. Zhao, G. Sheng, J. Hu, C. Chen, X. Wang, The adsorption of $\mathrm{Pb}$ (II) on $\mathrm{Mg} 2 \mathrm{Al}$ layered double hydroxide, Chem. Eng. J., 171(2011) 167-74.

[15] M.T. Yagub, T.K. Sen, S. Afroze, H.M. Ang, Dye and its removal from aqueous solution by adsorption: a review, Adv. Coll. Int. Sci., 209 (2014)172-184.

[16] A. Srivastav, V.C. Srivastava, Adsorptive desulfurization by activated alumina, J. Hazard. Mater., 170 (2009) 11331140.

[17] Y. Önal, Kinetics of adsorption of dyes from aqueous solution using activated carbon prepared from waste apricot, J. Hazard. Mater., 137 (2006) 1719-1728.

[18] M. Anbia, S.A. Hariri, Removal of methylene blue from aqueous solution using nanoporous SBA-3, Desalination, 261(2010) 61-66.

[19] A. Sari, D. Mendil, M. Tuzen, M. Soylak, Biosorption of palladium (II) from aqueous solution by moss (Racomitrium lanuginosum) biomass: equilibrium, kinetic and thermodynamic studies. J. Hazard. Mater., 162 (2009) 874-879.

[20] K. Foo, B. Hameed, Insights into the modeling of adsorption isotherm systems, Chem. Eng. J., 156 (2010) 2-10.

[21] V. M.Abbasov, H. C. Ibrahimov, Adsorptive Desulfurization of the Gasoline Obtained from Low-Pressure Hydro cracking of the Vacuum Residue Using a Nickel/Bentonite Catalyst, Energy Fuels, 31 (2017) 5840-5843.

[22] Y. Yongxing, J. Li, L. Guangqian, L. Zhang, Novel method to synthesize Ni2P/SBA-15 adsorbents for the adsorptive desulfurization of model diesel fuel, J. Alloys Compd., 745 (2018) 467-476.

[23] C. Almeida, N. Debacher, A. Downs, L. Cottet, C. Mello, Removal of methylene blue from colored effluents by adsorption on montmorillonite clay, J. coll. Int. Sci., 332 (2009) 46-53.
[24] N.R. Shinde, A.V. Bankar, A.R. Kumar, S.S. Zinjarde, Removal of Ni (II) ions from aqueous solutions by biosorption onto two strains of Yarrowia lipolytica, J. Environ. Manage., 102 (2012) 115-124.

[25] A. Bera, T. Kumar, K. Ojha, A. Mandal, Adsorption of surfactants on sand surface in enhanced oil recovery: isotherms, kinetics and thermodynamic studies, Appl. Surf. Sci., 284 (2013) 87-99.

[26[ R. Labied, O. Benturki, A. E.Hamitouche, Adsorption of hexavalent chromium by activated carbon obtained from a waste lignocellulosic material: Kinetic, equilibrium, and thermodynamic study, Adsorp. Sci. Technol., 36 (2018) 1066-1099.

[27] A. Dada, A. Olalekan, A. Olatunya, O. Dada, Langmuir, Freundlich, Temkin and Dubinin-Radushkevich isotherms studies of equilibrium sorption of $\mathrm{Zn} 2+$ unto phosphoric acid modified rice husk, J. Appl. Chem., 3 (2012) 38-45.

[28] A. Rong, L. Meng, P. Liping, Y. Dongsheng, J. Wang, Y. Zhou, Kinetics Study of Gas Pollutant Adsorption and Thermal Desorption on Silica Gel, Appl. Sci., 7, 609 (2017) 1-11.

[29] M. Anbia, A.H. Davijani, Synthesis of L-Cysteine grafted nanoporous carbon (CMK-3) and its use as a new cadmium sorbent, Chem. Eng. J., 223(2013) 899-907.

[30] M. Gouamid, M. Ouahrani, M. Bensaci, Adsorption equilibrium, kinetics and thermodynamics of methylene blue from aqueous solutions using date palm leaves, Energy Procedia, 36(2013) 898-907. 